\title{
Microwave incinerated sugarcane bagasse ash (MISCBA) as a low cost adsorbent for the removal of zinc in aqueous solution
}

\author{
I. U. Salihi, S. R. M. Kutty, M. H. Isa, N. Aminu \& H. Ezerie \\ Civil Engineering Department, Universiti Teknologi PETRONAS, \\ Malaysia
}

\begin{abstract}
In this particular research, microwave incinerated sugarcane bagasse ash (MISCBA) obtained by incinerating the sugarcane bagasse was utilized as a low cost adsorbent for the removal of $\mathrm{ZnCl}_{2}$ metal ion from synthetic wastewater through the batch adsorption approach. It was realized that the thermal incineration of the sugarcane bagasse changed the morphological structure of the bagasse. In addition, the surface structure of the sugarcane bagasse has changed from non-porous to a porous surface after incineration. The effect of $\mathrm{pH}$ and contact time, adsorbent dosage and initial metal concentration was investigated in this study. A pH value of 6 was found to be optimum. Furthermore, the percentage of adsorption improves with an increase in contact time and a contact time of 180 mins was found to be optimum after attaining equilibrium with a removal efficiency of $96.3 \%$. The equilibrium data was well described by Freudlich as well as the Langmuir model with a correlation coefficient of 0.997 and 0.984 . The kinetic data fitted well into the pseudo-second order model.

Keywords: microwave incinerated sugarcane bagasse ash (MISCBA), aqueous solution, bagasse, adsorbent, heavy metals.
\end{abstract}

\section{Introduction}

With the increase in industrialization and technological advancements, the environment is faced with negative impacts caused by such development. Although, the emergence of such industries contributes to the growth of social and economic status of a nation, release of wastewater laden with heavy metal 
contaminants by these industries contributes in the deterioration of the human environment and as well the ecosystem.

The industries discharge their wastewater directly into flowing rivers with or without given proper treatment and this adversely affect the environment especially in places where reuse of surface water is mainly practiced. The contamination of surface water by industrial action has become a major concern to the general public and has been elevating worldwide in the past decades (Meena et al. [1]). Their occurrence in the aquatic system has leads to major health issues faced by human, animals and plant as well (Kılıç et al. [2]). These metals contaminates not only the earth's water but also the underground water by seeping through the soil when rained or snowed (Mosa [3]). Due to this, regulatory bodies have enacted guidelines to be followed for the treatment of wastewater containing heavy metals before it is discharge into the environment.

Various techniques have been developed for the removal of these metals from wastewater including electrochemical processes, ion-exchange, membrane filtration, adsorption, chemical precipitation, coagulation, vacuum evaporation and floatation (Kılıç et al. [2]) etc. Nevertheless, the use of these techniques are not cost effective neither user friendly (Feng et al. [4]). Bio-sorption process is among the most suitable technology for the treatment of wastewater laden with heavy metals. It is a promising substitute for the traditional techniques used due to its availability, no nutrient requirement, reduced volume of waste sludge and also found in low cost (Deng and Ting [5]). In view of this, biomaterials have stand out to be an economical and user friendly alternative (Ahluwalia and Goyal [6]). Several biomaterials have been studied as an adsorbent for the removal of heavy metals from aqueous solution. Agricultural by-products have extensively been studied for the removal of heavy metals from solution. These includes, rice husk, peanut, saw dust, orange peel, wool, leaves, banana peel, peat, pine bark, sugarcane bagasse and onion (Wan Ngah and Hanafiah [7]).

Sugarcane bagasse possess some potentiality to be utilized as adsorbent for the removal of heavy metals from aqueous solution, this is because of its high lignin, hemicelluloses, cellulose, and carbon content (Guan et al. [8]). The use of raw sugarcane bagasse as an adsorbent has been reported by some authors (Basso et al. [9]). However, due to its low adsorption capacity for heavy metals removal, some authors reported to have given different modification for raw sugarcane bagasse waste as a tangible material for an adsorbent, especially by altering its properties in order to enhance its efficiency. In this particular study, the potentiality of utilizing microwave incinerated sugarcane bagasse ash (MISCBA) as a low cost adsorbent for the removal of Zinc from aqueous solution has been investigated.

\section{Materials and method}

\subsection{Adsorbent}

Sugarcane bagasse was obtained from a local juice maker at Botah, Malaysia, after all the cane juice has been extracted. It was then manually cut to an average size 
of $10 \mathrm{~cm}$ and washed several times with tap water in order to remove all dirt's and impurities from it; the bagasse was further washed with distilled water in order to enhance its purity from any contaminant. It was then dried in oven at $105^{\circ} \mathrm{C}$ for 24 hours until all its moisture was evaporated and constant weight was achieved. The dried bagasse was then grinded to a size of $6 \mathrm{~mm}$ using a laboratory grinder. The material was then incinerated at $500^{\circ} \mathrm{C}$ using a microwave oven incinerator for a complete process of 3 hours. The MISCBA was then grinded in a laboratory still mill and then sieved in the size range of $100-150 \mu \mathrm{m}$, the resulting powder was immersed in a week acid (5\% sulphuric acid) for 24 hours; the purpose of this procedure is to adjust the $\mathrm{pH}$ of the MISCBA into the acidic state to allow the adsorption process to occur. The resulting material was thoroughly washed with distilled water until a ph $4.25 \mathrm{pH}$ was achieved, the washed sample was then dried in an oven at $70^{\circ} \mathrm{C}$ for 3 hours and was then stored in an airtight container before use.

\subsection{Adsorbate}

A stock solution of $1000 \mathrm{mg} / \mathrm{L}$ of zinc was prepared by dissolving its corresponding salt chloride $\left(\mathrm{ZnCl}_{2}\right)$ in $1 \mathrm{~L}$ of ionized water to form an aqueous solution. Further required concentrations were achieved by diluting the stock solution using distilled water. To ensure the homogeneity of both the standard and stock solution, they are stirred for 1hour using magnetic hot plate stirrer at 100 $\mathrm{rpm}$ and $30^{\circ} \mathrm{C}$. All chemicals employed are of analytical grade, obtained from Merck (Germany).

\subsection{Experimentation}

Batch adsorption studies were carried out using series of Erlenmeyer flask containing $100 \mathrm{~mL}$ of synthetic solution and MISCBA dosage. The flasks were agitated using orbital shaker (Protech model 722) at $150 \mathrm{rpm}$ and at room temperature $\left(27 \pm 1^{\circ} \mathrm{C}\right)$ until the equilibrium were reached. The final settled solution was then filtered using a Whatsman cellulose acetate membrane filter of $0.45 \mu \mathrm{m}$. Filtered solutions are analyzed for its zinc metal content using Atomic Adsorption Spectrometer, AAS (Model AA 6800 Shimadzu). The effect of pH of the initial aqueous solution on the equilibrium uptake of $\mathrm{ZnCl}_{2}$ ion was analyzed upon a $\mathrm{pH}$ range from 1 to 8 . The $\mathrm{pH}$ of the solution was adjusted using $2.0 \mathrm{~N}$ Hydrochloric acid and 1.5N Sodium hydroxide (NaoH) solutions. $500 \mathrm{mg}$ of MISCBA was placed into each of the flasks. The flasks were clamped in an orbital shaker and agitated at a speed of $150 \mathrm{rpm}$ for a period of 2 hours. The $\mathrm{pH}$ of the solution was measured using a pH meter (Model EW 53013, Hach Sension 1). The effect of initial metal ion concentration on the adsorption of zinc was studied by varying the metal concentration from 1 to $200 \mathrm{mg} / \mathrm{L}$. The $\mathrm{pH}$ of the solution was adjusted to the optimum $\mathrm{pH}$ before the addition of adsorbent. The effect of adsorbent dosage was also varied from 2 to $12 \mathrm{~g} / \mathrm{L}$. The batch studies were also conducted as a function of contact time $(1,5,10,2030,60,90,120,150,180,210$ and 240min) for maximum adsorption until equilibrium was achieved. The percentage removal $(\mathrm{R})$ of Zinc was calculated by: 


$$
R=\frac{(C i-C e)}{C i} X 100 \%
$$

where, $\mathrm{Ci}$ and $\mathrm{Ce}$ are the initial and equilibrium concentration in $(\mathrm{mg} / \mathrm{L})$ in the solution. The adsorptive capacity of the metal ions in $(\mathrm{mg} / \mathrm{mg})$ was computed by:

$$
\mathrm{q}=\frac{(C i-C e) \mathrm{V}}{W}
$$

where $\mathrm{q}$ is the capacity of adsorption $(\mathrm{mg} / \mathrm{mg}), \mathrm{Ci}$ and $\mathrm{Ce}$ are initial and equilibrium concentration of the metal solution $(\mathrm{mg} / \mathrm{L}), \mathrm{V}$ is the volume of the solution used (L) and $\mathrm{W}$ is the weight of adsorbent $(\mathrm{g})$.

The isotherm and kinetics models used in this study are shown in Tables 1 and 2 below.

\begin{tabular}{|c|c|c|c|}
\hline Isotherm model & Equation & Parameters & Reference \\
\hline Langmuir & $\frac{x}{m}=\frac{a b C_{e}}{1+b C_{e}}$ & $\begin{array}{l}\frac{x}{m}=\text { Amount of adsorbate } \\
\text { adsorbed per unit mass of } \\
\text { adsorbate }(\mathrm{mg} / \mathrm{g}) \text {; } \\
C_{e}=\text { equilibrium concentration } \\
\text { of adsorbate in solution after } \\
\text { adsorption }(\mathrm{mg} / \mathrm{L}) \text {; } \\
\text { a and b are constant. }\end{array}$ & $\begin{array}{c}\text { (Isa et al. } \\
[10])\end{array}$ \\
\hline Freundlich & $\frac{x}{m}=\mathrm{K}_{\mathrm{f}} C_{e}^{1 / n}$ & $\begin{array}{l}\mathrm{Kf}=\text { Freundlich constant }(\mathrm{mg} / \mathrm{g}) ; \\
\mathrm{n} \text { is a constant. }\end{array}$ & $\begin{array}{l}\text { (Isa et al. } \\
\text { [10]) }\end{array}$ \\
\hline
\end{tabular}

Table 1: Isotherm equations used in the study.

Table 2: Kinetic equations used in the study.

\begin{tabular}{|c|c|l|c|}
\hline Kinetic Model & Equation & \multicolumn{1}{|c|}{ Parameters } & Reference \\
\hline $\begin{array}{c}\text { Pseudo first- } \\
\text { order }\end{array}$ & $\ln \left(\mathrm{q}_{\mathrm{e}}-\mathrm{q}_{\mathrm{t}}\right)=\ln \mathrm{q}_{\mathrm{e}}-\mathrm{k}_{1} \mathrm{t}$ & $\begin{array}{l}\mathrm{Q}_{\mathrm{e}}(\mathrm{mg} / \mathrm{g})=\text { equilibrium } \\
\text { adsorption capacity; } \\
(\mathrm{mg} / \mathrm{g}) \quad=\quad \text { amount of } \\
\text { adsorbate adsorbed at time } \mathrm{t} \\
(\mathrm{min}) ; \mathrm{k}_{1}\left(\mathrm{~min}^{-1}\right)=\text { pseudo } \\
\text { first-order constant. }\end{array}$ & $\begin{array}{c}\text { McKay } \\
[11])\end{array}$ \\
\hline $\begin{array}{c}\text { Pseudo second- } \\
\text { order }\end{array}$ & $\frac{t}{q_{t}}=1 / \mathrm{k}_{2} \mathrm{q}_{\mathrm{e}}{ }^{2}+\frac{t}{q_{e}}$ & $\begin{array}{l}\mathrm{K}_{2}\left(\mathrm{~g} \cdot \mathrm{mg}^{-1} \cdot \mathrm{min}^{-1}\right)=\mathrm{pseudo} \\
\text { second-order constant. }\end{array}$ & $\begin{array}{c}\text { (Aharoni } \\
\text { and } \\
\text { Tompkins } \\
\text { [12]) }\end{array}$ \\
\hline
\end{tabular}




\section{Results and discussion}

\subsection{Effect of pH}

Adsorption of metal ion by an adsorbent is greatly influenced by the $\mathrm{pH}$ of the adsorbate solution. This is because of the competitive nature between hydrogen ions and positively charged metal ions struggling for an active site of the adsorbent (Rafatullah et al. [13]). Figure 1 shows the effect of $\mathrm{pH}$ on the adsorption of zinc. It is evident from the plot that the adsorption of zinc by MISCBA is relied upon the $\mathrm{pH}$ of the solution. Removal efficiency of zinc increases with an increase in solution $\mathrm{pH}$ and attaining a maximum removal efficiency of $96.2 \%$ at $\mathrm{pH} 8$. Though, literally for hydroxide precipitation, precipitation of zinc begins at a $\mathrm{pH}$ greater than 6 (Metcalf et al. [14]). Based on this, a $\mathrm{pH}$ of 6 having a removal efficiency of $86.2 \%$ is considered to be optimum for further studies. This is comparable to the result obtained by (Peternele et al. [15]) on the removal of metal ions by low cost adsorbent from an aqueous solution.

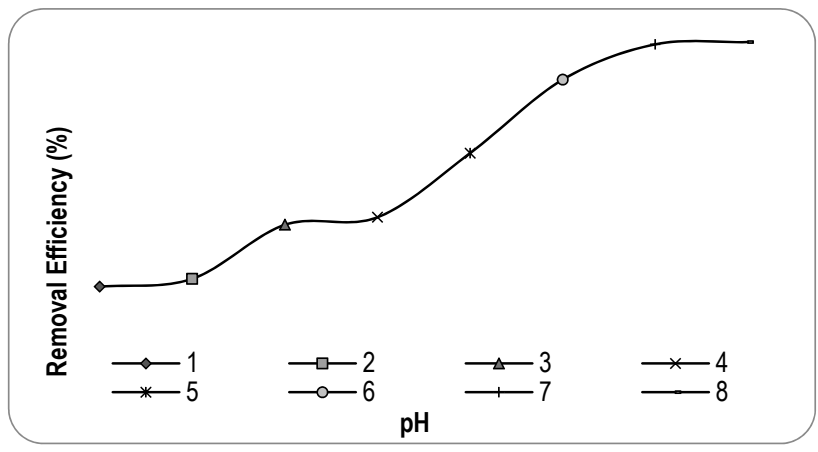

Figure 1: Effect of $\mathrm{pH}$ on the adsorption of metal ion zinc (initial concentration $=100 \mathrm{mg} / \mathrm{L}$, agitation speed $=150 \mathrm{rpm}$, temperature $=27 \pm 1{ }^{\circ} \mathrm{C}$, contact time $=120$ mins and adsorbent dosage $=5.0 \mathrm{~g} / \mathrm{L})$.

\subsection{Effect of contact time}

Preliminary studies were carried out in order to ascertain the optimum time taken to reach equilibrium adsorption. The results obtained are presented in Figure 2. From the plot it can be seen that higher percentage of removal was noticed in the first 20 mins and there is no substantial removal was realized after 180 mins. The high removal efficiency at the initial contact time is mainly related to the available surface area of MISCBA, as the contact time increase the surface of the adsorbent will be worn out and become lessen, at this stage, the efficiency of removal is controlled by the transport rate from the exterior to the interior sites of the adsorbent material (Rafatullah et al. [13]). Contact time of $180 \mathrm{mins}$ is considered to be optimum in this study and maintained for subsequent studies. Similar result was obtained by (Isa et al. [10]) in the adsorption of metal ions using low cost sorbent in aqueous solution. 


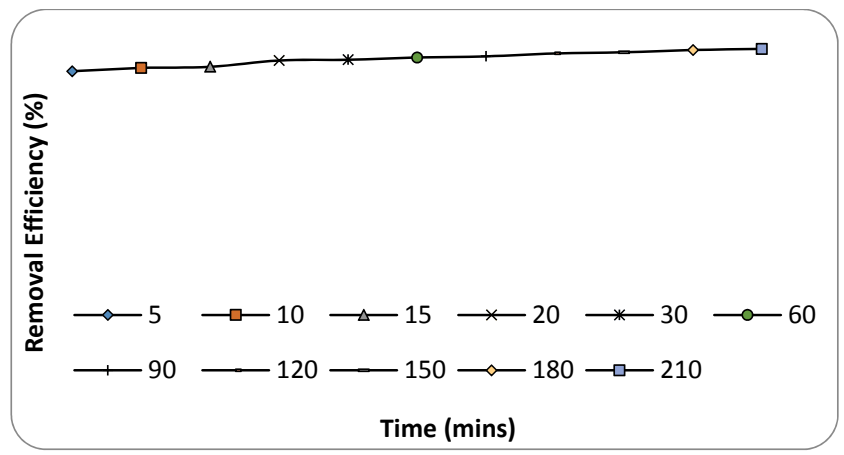

Figure 2: $\quad$ Effect of contact time on the adsorption of metal ion zinc (initial concentration $=100 \mathrm{mg} / \mathrm{L}$, agitation speed $=150 \mathrm{rpm}$, temperature $=$ $27 \pm 1^{\circ} \mathrm{C}, \mathrm{pH}=6.0$ and adsorbent dosage $\left.=5.0 \mathrm{~g} / \mathrm{L}\right)$.

\subsection{Effect of adsorbent dosage}

Effect of MISCBA on the adsorption of Zinc was investigated by varying the adsorbent dosage from 2 to $12 \mathrm{~g} / \mathrm{L}$. Other parameters such as $\mathrm{pH}$, contact time were set to the optimum value obtained; initial metal concentration of the metal ion was kept constant in its initial value. Figure 3 shows the plot of the effect of adsorbent dosage on the removal efficiency of zinc. It is evident from the plot that rate of removal increases with an increase in MISCBA dosage, literally this is attributed to the availability of more adsorption sites at increased attentiveness of the adsorbent material with regard to complexation of metal ions (Ahmad et al. [16]). Removal percentage of zinc increased from $73.5 \%$ to $91.1 \%$ with an increase in MISCBA adsorbent at equilibrium condition.

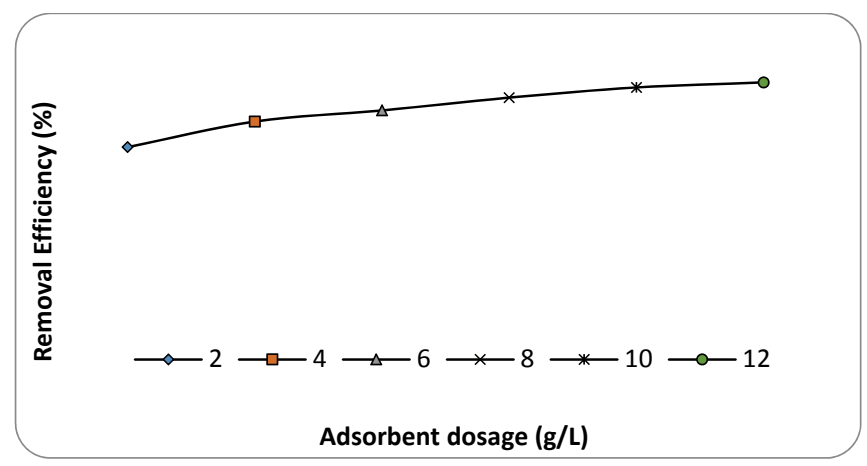

Figure 3: $\quad$ Figure 3: $\quad$ Effect of adsorbent dosage on the adsorption of metal ions (initial concentration $=100 \mathrm{mg} / \mathrm{L}$, agitation speed $=150 \mathrm{rpm}$, contact time $=180$ mins, temperature $=27 \pm 1^{\circ} \mathrm{C}, \mathrm{pH}=6.0$ and adsorbent dosage $=5.0 \mathrm{~g} / \mathrm{L}$ ). 


\subsection{Effect of initial metal ion concentration}

Concentration of metal ion in the solution plays a vital role in the adsorption process as a major steering force to outweigh the mass transport resistance involving the solution as well as solid stages (Rafatullah et al. [13]). At lower concentration it is expected that the adsorption rate will be higher and vice versa. Figure 4. Show that percentage of removal decreases with increasing metal ion concentration in the aqueous solution. Adsorption of zinc by MISCBA is found to be relied on the initial concentration of the adsorbate to a greater extent.

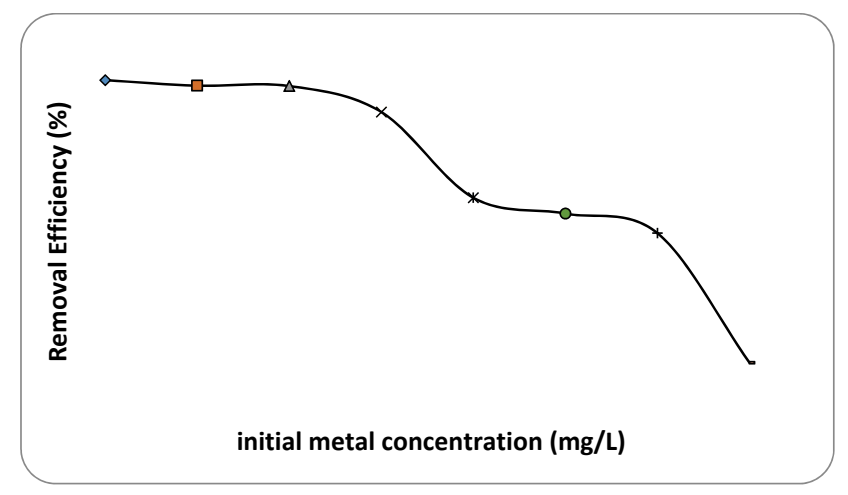

Figure 4: $\quad$ Effect of initial metal ion concentration on the adsorption of metal ion zinc (agitation speed $=150 \mathrm{rpm}$, contact time $=180 \mathrm{mins}$, temperature $=27 \pm 1^{\circ} \mathrm{C}, \mathrm{pH}=6.0$ and adsorbent dosage $=5.0 \mathrm{~g} / \mathrm{L}$ ).

\subsection{Adsorption isotherms}

In the modeling process for the analysis and design of an adsorption system, an adsorption isotherm tends to be an essential tool in understanding the adsorption behavior between the adsorbent and the adsorbate. Freundlich and Langmuir equations were employed in order to relate the isotherm upon the adsorption of Zinc. The isotherm constants obtained graphically for both Langmuir and Freundlich are presented in Table 3 below.

Table 3: Constants of isotherm and correlation coefficients.

\begin{tabular}{|c|c|c|c|c|c|}
\hline \multicolumn{3}{|c|}{ Langmuir isotherm } & \multicolumn{3}{c|}{ Freundlich isotherm coefficients } \\
\hline $\mathrm{a}$ & $\mathrm{b}$ & $\mathrm{R}^{2}$ & $\mathrm{~K}_{\mathrm{f}}$ & $\mathrm{R}^{2}$ & $\mathrm{n}$ \\
\hline 28.57 & 0.984 & 0.9210 & 8.76 & 0.997 & 1.17 \\
\hline
\end{tabular}

The Freundlich isotherm model fitted well into the experiment data with a higher correlation coefficient near unity. With $n>1$ adsorption is a physical process and also represents a favourable adsorption condition with heterogeneous activated carbon surface and is the most common value usually obtained which 
can be link to other factors that lessens the relationship between adsorbent and adsorbate while enhancing the surface density (Reed and Matsumoto [17]). Higher value of correlation coefficient was also obtained for Langmuir isotherm, which is the main factor that is used to describe the capability of the adsorption process and which indicates that the adsorption data fitted well into the model with a maximum adsorption capacity for Zinc of $28.57 \mathrm{mg} / \mathrm{g}$.

\subsection{Adsorption kinetics}

Adsorption data were analyzed using two different kinetic models namely pseudo first-order and pseudo second-order models in order to establish the adsorption mechanism that is responsible for the removal of Zinc. Figure 5 and 6 display the linear plots of the kinetic models (Pseudo first-order and Pseudo second-order). Kinetic constants obtained are shown in Table 4. Pseudo first-order with $\mathrm{R}^{2}=0.825$ indicates that the model has no satisfactory value to be predicted as a suitable model while a value $\mathrm{R}^{2}>0.99$ shows a very much ideal correlation value to be perfect model. Hence, it can be established that the adsorption of Zinc onto MISCBA perfectly follows the pseudo-second-order kinetic model. Indicating a chemisorptions process (Izanloo and Nasseri [18]).

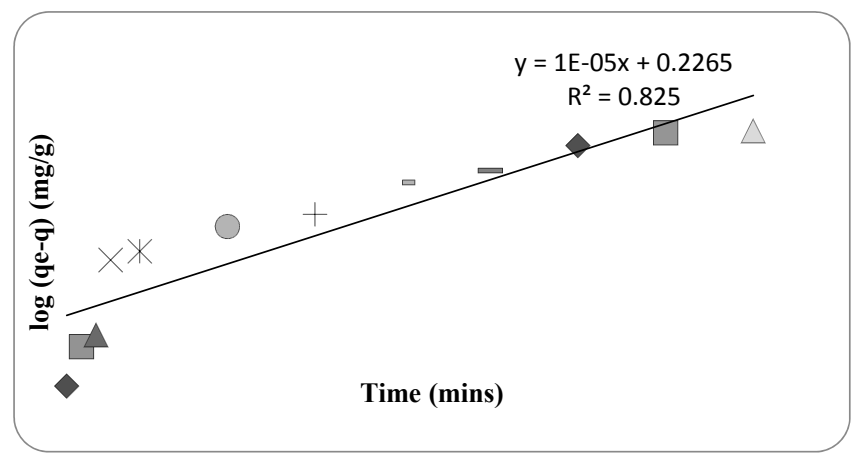

Figure 5: Pseudo first-order kinetic plot for the adsorption of metal ion zinc.

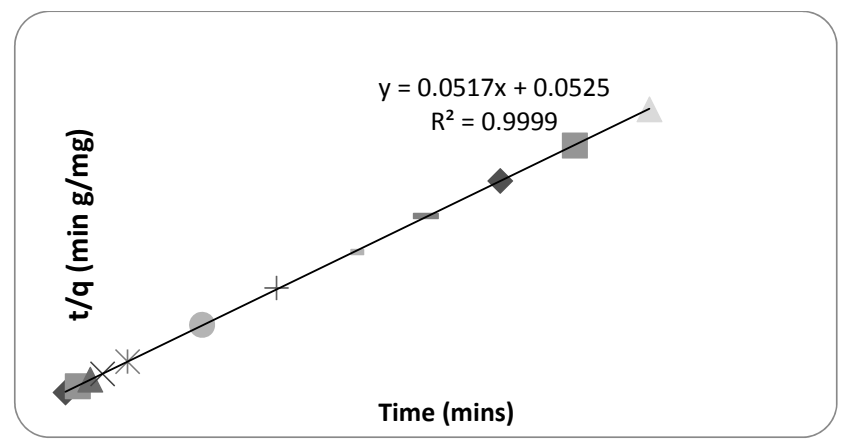

Figure 6: Pseudo second-order kinetic plot for the adsorption of metal ion zinc. 
Table 4: Kinetic models reaction rate constants for zinc adsorption.

\begin{tabular}{|c|c|c|c|}
\hline Kinetic model & $\mathrm{R}^{2}$ & $\mathrm{~K}$ & Equation \\
\hline Pseudo first-order & 0.825 & 0.007 & $\mathrm{y}=1 \mathrm{e}^{-05} \mathrm{x}+0.2226$ \\
\hline Pseudo second-order & 0.999 & 0.051 & $\mathrm{y}=0.051 \mathrm{x}+0.052$ \\
\hline
\end{tabular}

\section{Conclusion}

The study indicates that MISCBA have the capability to adsorb Zinc from aqueous solution. The removal efficiency is depended upon the solution $\mathrm{pH}$ and contact time with an optimum pH 6 and an equilibrium contact time 3 hours. Maximum adsorption capacity was found to be $28.57 \mathrm{mg} / \mathrm{g}$. The adsorption isotherm of the removal is described by both Freundlich and Langmuir isotherm models. Pseudo second-order fitted well into the adsorption data which implies a chemisorptions process between the adsorbent and the adsorbate.

\section{Acknowledgements}

The authors wish to acknowledge the research grant provided by Fundamental Research Grant Scheme (FRGS) that lead to the realization of this work and also Universiti Teknologi PETRONAS (UTP) for supporting this work. We are also thankful to Environmental Laboratory technologists for their assistance.

\section{References}

[1] A. K. Meena, K. Kadirvelu, G. Mishraa, C. Rajagopal, and P. Nagar, "Adsorption of $\mathrm{Pb}$ (II) and $\mathrm{Cd}$ (II) metal ions from aqueous solutions by mustard husk," Journal of hazardous materials, vol. 150, pp. 619-625, 2008.

[2] M. Kılıç, Ç. Kırbıyık, Ö. Çepelioğullar, and A. E. Pütün, "Adsorption of heavy metal ions from aqueous solutions by bio-char, a by-product of pyrolysis," Applied Surface Science, vol. 283, pp. 856-862, 10/15/ 2013.

[3] S. M. A. E. H. Mosa, "Adsorption of some heavy metals and ( $\mathrm{Mg}, \mathrm{Ca}$ ) ions from aqueous solutions by using different environmental residuals as a cheap adsorbents at optimum conditions," Science, vol. 2, pp. 1-5, 2014.

[4] N. Feng, X. Guo, S. Liang, Y. Zhu, and J. Liu, "Biosorption of heavy metals from aqueous solutions by chemically modified orange peel," Journal of Hazardous Materials, vol. 185, pp. 49-54, 1/15/ 2011.

[5] S. Deng and Y. P. Ting, "Fungal biomass with grafted poly(acrylic acid) for enhancement of $\mathrm{Cu}(\mathrm{II})$ and $\mathrm{Cd}(\mathrm{II})$ biosorption," Langmuir, vol. 21, pp. 5940-5948, 2005.

[6] S. S. Ahluwalia and D. Goyal, "Microbial and plant derived biomass for removal of heavy metals from wastewater," Bioresource Technology, vol. 98, pp. 2243-2257, 9/2007. 
[7] W. Wan Ngah and M. Hanafiah, "Removal of heavy metal ions from wastewater by chemically modified plant wastes as adsorbents: A review," Bioresource Technology, vol. 99, pp. 3935-3948, 2008.

[8] B. T. Guan, P. A. Latif, and T. Y. Yap, "Physical preparation of activated carbon from sugarcane bagasse and corn husk and its physical and chemical characteristics," 2013.

[9] M. Basso, E. Cerrella, and A. Cukierman, "Lignocellulosic materials as potential biosorbents of trace toxic metals from wastewater," Industrial \& Engineering Chemistry Research, vol. 41, pp. 3580-3585, 2002.

[10] M. H. Isa, N. Ibrahim, H. A. Aziz, M. N. Adlan, N. H. M. Sabiani, A. A. L. Zinatizadeh, et al., "Removal of chromium (VI) from aqueous solution using treated oil palm fibre," Journal of Hazardous Materials, vol. 152, pp. 662-668, 4/1/2008.

[11] Y. Ho and G. McKay, "Comparative sorption kinetic studies of dye and aromatic compounds onto fly ash," Journal of Environmental Science \& Health Part A, vol. 34, pp. 1179-1204, 1999.

[12] C. Aharoni and F. Tompkins, "Kinetics of adsorption and desorption and the Elovich equation," Advances in Catalysis, vol. 21, pp. 1-49, 1970.

[13] M. Rafatullah, O. Sulaiman, R. Hashim, and A. Ahmad, "Adsorption of copper (II), chromium (III), nickel (II) and lead (II) ions from aqueous solutions by meranti sawdust," Journal of Hazardous Materials, vol. 170, pp. 969-977, 10/30/2009.

[14] L. Metcalf, H. P. Eddy, and G. Tchobanoglous, Wastewater engineering: treatment, disposal, and reuse. New York [etc.]: McGraw-Hill, 2004.

[15] W. S. Peternele, A. A. Winkler-Hechenleitner, and E. A. Gómez Pineda, "Adsorption of $\mathrm{Cd}(\mathrm{II})$ and $\mathrm{Pb}(\mathrm{II})$ onto functionalized formic lignin from sugar cane bagasse," Bioresource Technology, vol. 68, pp. 95-100, 4/1999.

[16] A. Ahmad, M. Rafatullah, O. Sulaiman, M. H. Ibrahim, Y. Y. Chii, and B. M. Siddique, "Removal of $\mathrm{Cu}(\mathrm{II})$ and $\mathrm{Pb}(\mathrm{II})$ ions from aqueous solutions by adsorption on sawdust of Meranti wood," Desalination, vol. 247, pp. 636-646, 10/2009.

[17] B. E. Reed and M. R. Matsumoto, "Modeling cadmium adsorption by activated carbon using the Langmuir and Freundlich isotherm expressions," Separation science and technology, vol. 28, pp. 2179-2195, 1993.

[18] H. Izanloo and S. Nasseri, "Cadmium removal from aqueous solutions by ground pine cone," Iranian Journal of Environmental Health Science \& Engineering, vol. 2, pp. 33-42, 2005. 